\title{
Fragilidad del futuro: fenomenología de la vejez
}

\author{
Marcela Venebra \\ Universidad Autónoma del Estado de México \\ mvenebram@uaemex.mx \\ https://orcid.org/0000-0003-3880-8155
}

Resumen: La tesis central de este artículo es que la vejez no se confunde con la enfermedad, y que su distinción arraiga en la dimensión temporal del cuerpo vivido. El tiempo del cuerpo es elemento ingrediente de la autocaptación (autoconstitución) del sí mismo en el horizonte de sus posibilidades y potencialidades, que en la vejez aparecen bajo una condición frágil y desgastada. Expongo esta tesis en tres partes principales: en la primera trato de deslindar las dimensiones del tiempo de la naturaleza y el tiempo subjetivo en el decurso constitutivo del cuerpo propio. En estas distinciones la vejez se esclarece, respecto del tiempo de la naturaleza, como la fase de cumplimiento normal o del más amplio y unitario desarrollo del cuerpo como cosa viviente. En la segunda parte, defino la fragilidad de futuro como especificidad estructural del horizonte temporal de la vejez; finalmente, en la tercera y última parte, exploro la incidencia de esta condición temporal en la forma de autocaptación (o auto-constitución) del yo, y en la significación (historización) de su propio cuerpo en la vejez. El marco metodológico de este estudio está centralmente tomado de los análisis husserlianos de la constitución en Ideas II. Palabras clave: vejez; fenomenología; corporalidad; temporalidad; identidad

\begin{abstract}
Fragility of the Future: Phenomenology of the Old-age". The central thesis of this paper is that old-age is not confused with illness, and its distinction is rooted in the temporal dimension of the living body. The body's time is an ingredient of the self-consciousness (selfconstitutive) in the horizon of the possibilities and potentialities of the ego, which in old-age appear under a fragile and worn condition. I present this thesis in three main parts: first, I try to distinguish the dimensions of time of nature and subjective time. In these distinctions old age is clarified, with respect to the time of nature, as the phase of normal fulfillment or of the broadest and unitary development of the body as a living thing. In the second part I define the fragility of the future as the structural specificity of the time horizon of old-age. Finally, in the third part I explore how this temporal condition determines the self-consciousness (self-constitution) and the signification (historization) of its own body in old-age. The methodological frame of this investigation is taken from the Husserlian analysis of constitution in Ideas II.
\end{abstract}

Keywords: old-age, phenomenology, corporeality, temporality, identity 


\section{Introducción ${ }^{1}$}

La vejez no es equivalente a un estado de anormalidad sino el cumplimiento $^{2}$ esperable de una normalidad inherente al cuerpo como cosa viva o viviente. El desgaste del cuerpo en la vejez expresa el cumplimiento de funciones y capacidades corporales y un horizonte de futuro no enfermo sino frágil ${ }^{3} \mathrm{o}$, en cierto sentido, pleno, esto es, como plenitud del cuerpo en tanto cosa viva y vivida. Esta fragilidad no es solo física o material sino del yo de las capacidades y las posibilidades de acción y experiencia, que se estrechan en el horizonte de lo ya vivido, ya experimentado y hecho por el sí mismo.

Fenomenológicamente considerada, la vejez es envejecimiento, punto culminante del desarrollo corporal, es cumplimiento normal y esperable del despliegue (también comprensible como desarrollo) del cuerpo como cosa viva o viviente (Leib), y como tal es un campo de significado que el yo se apropia; la vejez tiene a su vez una faz espiritual, histórica y cultural, y un subsuelo o sustrato sensible, un núcleo anónimo de afección, irreductible y siempre presente. Lo que interesa aquí es comprender cómo se constituye el cuerpo envejecido y cuáles son las determinaciones experienciales de la vejez que no se confunden con la enfermedad. La constitución abarca las peculiaridades estructurales de este modo de experiencia del sí mismo encarnado, peculiaridades como la condición existencial subjetivo-objetiva de la persona humana, que es el punto de partida y referencia de toda reflexión fenomenológica sobre el mundo de la vida. El yo

\footnotetext{
1 Agradezco sinceramente puntuales observaciones que los árbitros hicieron a este estudio. Considero que el texto ganó precisión y claridad a partir de sus amables lecturas.

2 El "cumplimiento" de la semilla es el brote, o la flor, como el cumplimiento de la flor en la rama es el fruto, o en el jarrón la flor marchita. Me referiré aquí al "cumplimiento" como punto de llegada de las etapas de desarrollo vital del cuerpo. El término mismo tiene un sentido fenomenológico, pero no estrechamente técnico: se cumplen en el cuerpo funciones orgánicas normales, se cumplen etapas contenidas en el presente pleno, el cuerpo se desarrolla y las marcas de su desa416 rrollo, de la infancia a la vejez son tendencias cumplidas en la continuidad de la vida corporal. 3 En un estudio de 2018, Susan Pickard analiza la vejez desde el punto de vista patológico, del que este análisis toma clara distancia. La definición de la vejez en el estudio de Pickard se establece en relación con una condición primariamente material del cuerpo, que reconoce las limitaciones del discurso médico pero incurre -sin perder de vista los contenidos históricos- en su asociación inmediata con las atribuciones valorativas de la salud y la enfermedad: "de hecho, la etiqueta de fragilidad refiere ciertos valores sociales atribuidos a la salud (productividad, autonomía, rapidez, compromiso social, etcétera) que sugieren una particularmente tardía, 'economía moral del cuerpo frágil' en sentido moderno" ( $c f$. Pickard, S., "Health, Illness and Frailty in Old Age: a Phenomenological Exploration”, en: Journal of Aging Studies, v. XLVII (2018), p. 25).
} 
constituye, experiencia, se apropia la carne, la hace suya como su cuerpo (o no). Los procesos de apropiación del cuerpo, en términos husserlianos, de su constitución como haber, se relacionan (en modos descriptibles) con el decurso constitutivo de la identidad del yo. Envejece el cuerpo y envejece el yo, y el yo se vive, vive su vida desde la vejez de su cuerpo. Como estado del cuerpo, la vejez es ingrediente ${ }^{4}$ de la captación del sí mismo y de la autoconstitución del sí, a través de habituaciones y sedimentaciones que vertebran la propiedad (o el haber) del cuerpo vivido.

La vejez como una fase del desarrollo del cuerpo vivido -la fase de su cumplimiento último como organismo vivo- se caracterizaría por la estructura específica de un horizonte de futuro frágil en relación con las posibilidades y capacidades del yo y con las determinaciones materiales del cuerpo. El cuerpo en la vejez se constituye o experiencia por el sí mismo, desde una condición de fragilidad fisica o material -cada vez más presente- y de posibilidades experienciales del yo cada vez más estrechas: en la vejez el futuro se adelgaza, se angosta el sentido de la novedad y la indeterminación de la expectativa. La fragilidad del futuro es un núcleo irradiante de significados y valoraciones que son espiritual o culturalmente instituidas, últimamente relativas a una cierta idea (metafísica, mítica, científica) pero ciertamente totalizante, y unitaria, de la vida. Desarrollo este argumento en tres momentos principales, en el primero trato de deslindar las dimensiones de la temporalidad que irradian del cuerpo: el tiempo de la naturaleza y el tiempo subjetivo. En un segundo momento me aboco a la descripción de la fragilidad de futuro como el rasgo estructural del horizonte del tiempo subjetivo en la vejez. En el tercer y último apartado trato los modos de apropiación del cuerpo e identificación del yo en el haber de su cuerpo desgastado, pero no enfermo ni -necesariamente-disfuncional. El objetivo o alcance último de este breve estudio es aportar una definición de vejez que la distinga de la enfermedad y que alcance a clarificar, incluso, la naturaleza de su histórica relación con lo patológico.

\footnotetext{
4 Es ingrediente porque es del yo, forma parte constitutiva del yo, de un yo puedo que se reconoce envejecido, y se vive en el desgaste de su cuerpo. La cualidad antropológica del ser objeto y sujeto para sí, implica desde la pasividad de la carne (aquí puesta como cuerpo vivo), la condición encarnada de la vida de conciencia. Los estados corporales son ingredientes de la vida de conciencia, porque es el yo quien padece dolor, porque, en tal caso, el dolor no se reduce a una avería del cuerpo, me vivo a mí mismo en y desde el dolor, etcétera. El dolor es del yo, como el placer es del yo, como vivencias, y así también la niñez y la infancia son momentos de la corriente de la vida de conciencia, mis vivencias de la infancia son momentos, trozos de ese tiempo, así también la vejez, en su compleja condición de estado corporal patentemente vivido desde el desgaste y la fragilidad.
} 


\section{Tiempo de la naturaleza y tiempo del cuerpo}

En su condición de cosa viviente el cuerpo es "órgano" de la naturaleza en el sentido en que el cuerpo implica su mundo entorno; en su extensión y condición orgánica el cuerpo viviente está sujeto a la rítmica natural y a la ciclicidad del entorno de las cosas vivas. En el ritmo circadiano de la alternancia diurna y nocturna se eslabona el cuerpo vivido en cuanto cosa viviente. El hambre, el cansancio, la necesidad de dormir no representan maneras de enlace, sino manifestaciones de la pertenencia del cuerpo como cosa viva a la naturaleza. El cuerpo viviente es un momento de la naturaleza ${ }^{5} \mathrm{y}$ esto significa una idea de naturaleza de fondo, como una totalidad continua ${ }^{6}$, o cuya continuidad totalizante implica un movimiento, o transmutaciones experienciables que integran lo que cualquiera reconoce como vida -desde el propio cuerpo-. Si fenomenológicamente el cuerpo vivo se constituye, se da en la captación de un movimiento posible (no determinado) es porque la vida se capta en el movimiento como cambio.

Husserl distingue entre el tiempo subjetivo, como la corriente inmanente de la temporalidad -lo conciencial en última instancia-, y el tiempo objetivo, como un tiempo homogéneo y medible, dejando en cierta ambigüedad la determinación de la materia medible ${ }^{7}$ en cuanto tal. Podemos reconocer, sin embargo,

\footnotetext{
5 "Interesa grandemente que este concepto pueda aplicarse, también, a cada cosa viviente que, en sí misma, representa una parte constituyente del mundo como un todo. Esto es ciertamente verdadero en cuanto a las cosas vivientes, como lo ha probado la embriologia" (Imanishi, K., El mundo de las cosas vivientes, Paz-Bonells, M. (trad.), Caracas: Instituto Venezolano de Investigaciones Científicas, 2011, p. 58). Afirmar, pues, que el cuerpo es un momento de la naturaleza, significa solo señalar el modo en que en su condición viva se inserta en el decurso o continuum de la naturaleza como entorno inmediato y relacional, dinámico en todo momento. La respiración, la transpiración, lo que Husserl reconoce como afecciones en Imanishi se explica como correspondencia o extensión (expansión relacional) de la cosa cuerpo en su entorno vital.

6 La "continuidad" se refiere a las relaciones que estructuran el entorno del sujeto como una totalidad en sí misma, la de un orden de relaciones vitales: "Cada sujeto teje relaciones, como hilos de una araña, sobre determinadas propiedades de las cosas, entrelazándolas hasta configurar una sólida red que será portadora de su existencia" (von Uexküll, J., Andanzas por los mundos circundantes de los animales y los hombres, Guntin, M. (trad.), Buenos Aires: Cactus,

7 Husserl señala que el tiempo objetivo es el tiempo intersubjetivo, el uno y único para todos, este sin duda tiene su núcleo en la ciclicidad natural, pero la temporalidad natural como tal no es claramente distinguida: "En consideración objetiva puede tener toda vivencia, igual que todo ser real o todo momento entitativo real, su lugar en el tiempo objetivo uno y único; también lo tendrá, pues, la propia vivencia de percepción del tiempo y de representación del tiempo" (Husserl, E., Las lecciones sobre la conciencia interna del tiempo de 1905, Serrano de Haro, A. (trad.), Madrid: Trotta, 2002, p. 26). Las representaciones del tiempo entran en el orden mismo de la medida. Por lo que la medida del tiempo objetivo tendria como contenido el tiempo vivido de la naturaleza, el tiempo del cuerpo. Lo importante aquí es, pues, la distinción entre el tiempo objetivo como tiempo
} 418 2016, p. 52). 
que la ciclicidad de la naturaleza es esa materia, pero no coincide totalmente con su medida. El tiempo objetivo como tiempo homogéneo y representable en las unidades de medida de los meses a los milenios o las eras, de los segundos, pues, a las semanas, es la abstracción de la primera intuición del cambio en el entorno y en la afección y afectación continua ${ }^{8}$ del propio cuerpo en ese cambio. El tiempo de la física es un tiempo homogéneo y por ello medible (fraccionable) que se basa en la experiencia básica del tiempo natural o de la naturaleza. En sentido estricto, el tiempo de la naturaleza no es "tiempo" (no es exactamente medida del movimiento) sino una rítmica alternancia, cíclica, del día y la noche, de las estaciones, de las mareas y los cambios del mundo en torno ${ }^{9}$. El tiempo de la naturaleza es el tiempo del cuerpo porque el cuerpo es una cosa viviente o animal. La edad es la medida del tiempo objetivo sobre el cuerpo viviente porque la condición corporal está inscrita en la ciclicidad natural.

El despliegue del cuerpo viviente, en concreto, de sus horizontes de realización, se corresponde con la ciclicidad vital de todos los cuerpos vivos del entorno $\left(U m-W e l t^{10}\right)$. Si el primer referente de esta ciclicidad de acabamiento y renacimiento es la alternancia más inmediata del día y la noche, del sol y la luna

intersubjetivo uno, y el tiempo de la naturaleza como un ritmo perceptible y objetivable, representable y medible al que pertenece el propio cuerpo.

8 La afección señala nada más que el entretejimiento autosintiente del cuerpo propio en el tejido causal de la naturaleza física. La condición del cuerpo propio, su composición estructural, es el complejo de eso que Javier San Martín llama comunidad de base conciencia-mundo: "Es como si, más allá de la luz, el color y el sonido que habitan el mundo, dándole un contenido, hubiera una comunidad de base entre el cuerpo y el mundo que no puede ser interrumpida y que por tanto siempre está ahí, y que se nos muestra en los análisis del propio Husserl" (San Martín, J., "El contenido del cuerpo", en: Investigaciones Fenomenológicas, v. monográfico II: Cuerpo y alteridad, Madrid: UNED-SEFE, 2010, p. 176).

9 En todo caso, el problema estriba en aclarar el modo corporal en el que el tiempo subjetivo se relaciona con el tiempo de la naturaleza: "Todo lo mundano participa de la naturaleza... mediata o inmediatamente, en la esfera espacio-temporal todo lo que es mundano y real tiene su sitio; todo está aquí o allá y el lugar es determinable, como en general lo son los lugares, igual que todo lo que es espacio-temporal, es decir, determinable temporalmente por medio de instrumentos físicos, ya sean relojes de arena o de péndulo o cualquier otro tipo de cronómetro. De este modo, también todo lo no-sensible participa de la sensibilidad; es algo existente del mundo, algo que existe en el horizonte espacio-temporal que es uno" (Husserl, E., Experiencia y juicio. Investigaciones acerca de la genealogía de la lógica, Reuter, J. (trad.), México D.F.: UNAM, 1980, p. 35).

10 "Así queda abierta la puerta que conduce a los mundos circundantes, puesto que todo lo que un sujeto percibe se torna su mundo perceptual, y todo su obrar se vuelve su mundo efectual. Mundo perceptual y mundo efectual conforman juntos una unidad cerrada: el mundo circundante" (von Uexküll, J., p. 35). Es interesante ver la coincidencia de esta descripción de Uexküll de lo que corresponde al contenido del Um-Welt, y lo que Husserl considera como tal en Ideas II, o bien, entendido como mundo subjetivo, o mundo circundante personal. Cf. Husserl, E., Ideas relativas a una fenomenología pura y una filosofía fenomenológica, Libro II. Investigaciones filosóficas sobre la constitución, Zirión Quijano, A. (trad.), México D.F.: Fondo de Cultura Económica, 2005, §53, p. 256). 
en la bóveda celeste, es este según Cassirer ${ }^{11}$, el primer marcador de la rítmica ciclicidad a la que pertenece el cuerpo como cosa viva. El marcador originario de las horas es de carácter práctico (hay horas fastas y nefastas, claras y aciagas), hay horas de labor y horas de descanso. El sustrato impulsivo de las horas es el cansancio, el despertar, el hambre y las condiciones que el entorno ofrece como óptimas para el desenvolvimiento de las labores y del trabajo. El tiempo del cuerpo es el tiempo de la naturaleza. Los impulsos, que son del cuerpo y, luego, del yo (del cuerpo en su materialidad carnal), se corresponden con el continuum del ritmo natural, pero a la vez se circunscriben en la dialéctica de la pasividad y la actividad en la que el cuerpo vivido se constituye, de hecho, como cuerpo propio. El tiempo de la naturaleza es el tiempo del cuerpo como cosa viviente, pero como viviente es vivido, y el impulso está en el núcleo de su pasividad pre-egoica, en el aflujo temporal de la conciencia como vida subjetiva.

La temporalidad inmanente es el yo y su contenido, en la modalidad de la corriente -en red- que él polariza, unifica desde sí, un sí mismo como subjetividad encarnada, afectada continuamente, $y$, sin embargo, intocada. La corriente interna del tiempo no coincide con el tiempo de la naturaleza, aunque tampoco está ella misma en el tiempo. Sentir es temporalizar, la temporalización es la irradiación del presente hacia horizontes fluyentes de lo ocurrido, a lo esperable y de lo esperable en lo dado. La forma en la que las vivencias se ordenan no es, por principio, ni unilineal ni la de una mera sucesión. La vivencia presente, el punto cero del tiempo inmanente, implica en lo dable lo dado bajo la dimensión de lo recién dado (y retenido) y de lo antes dado (rememorable), entre el presente pleno, el aquí efectivo de la cosa dada, y la protención orientada por experiencias previas, por sedimentaciones en las que se trama lo esperable -basiquísimo- que completa continuamente la percepción de este momento de la cosa: "Cuando, por ejemplo, suena una melodía, la nota individual no desaparece del todo una vez que ha cesado el estímulo, o una vez que ha cesado el movimiento nervioso suscitado por el estímulo. Cuando la nueva nota suena, la precedente no ha desaparecido sin dejar rastro; de otro modo... tendriamos a cada instante un sonido... pero nunca la representación de una melodia"12.

Lo apresentado bordea la presencia y la orienta. En la constitución del cuerpo como órgano de la naturaleza se apresenta el despliegue del desarrollo

\footnotetext{
11 "La progresiva intelección de la diferencia entre el día y la noche, la luz y la oscuridad, es el nervio interior de toda evolución cultural humana" (Cassirer, E., Filosofia de las formas simbólicas II, México D.F.: Fondo de Cultura Económica, 2001, p. 132).

${ }^{12}$ Husserl, E., Lecciones de la conciencia interna del tiempo, p. 33.
} 
como tendencia natural del cuerpo en cuanto cosa viva. La flor viva a-presenta su marchitamiento. El nacimiento, el cumplimiento reproductivo y el marchitamiento -desgaste- que precede a la muerte o disolución definitiva del cuerpo en su materialidad, articulan o estructuran la captación del cuerpo como momento del decurso causal de la naturaleza. El nacimiento del cuerpo implica el horizonte de un despliegue tendente al cumplimiento de la vida en la plenificación de cada fase del desarrollo. Esto quiere decir que la vejez tiene un contenido "natural" fundado en el "contenido del cuerpo"13, en su vitalidad incluso antes que su vivencialidad autoconsciente. El desarrollo es el despliegue funcional de la cosa viviente: "No hay estructura de cosa viviente alguna, que haya estado completa desde su mismo nacimiento, sino que es el resultado del desarrollo gradual que significa su crecimiento. Todo crecimiento es un proceso viviente: así, cuando hablamos de la forma o la estructura de los organismos debe ser en términos de las cosas vivientes que son vitales. Cuando hablamos acerca de los organismos en cuanto entidades reales, debemos trabajar sobre la asunción de que están vivas ${ }^{14}$.

El desarrollo del cuerpo es su temporalidad natural. El primer horizonte temporal es, por así decir, el del tiempo del cuerpo. Esta temporalidad sería más bien pre-temporal, es decir, un ritmo cíclico, repetitivo e infinito, un ciclo que continuamente vuelve sobre su propio inicio ${ }^{15}$. El tiempo del cuerpo es el tiempo de la naturaleza y esa temporalidad no es acumulativa sino continuamente renovadora, de tal modo que el estado material del desgaste implica no un movimiento que cesa, sino una tendencia igualmente continua a la renovación de la vida en un sentido que rebasa la temporalidad individual, o

\footnotetext{
${ }^{13}$ El contenido del cuerpo es la carne en su enlace o, mejor, en su eslabonarse con el mundo en torno en cuanto cosa viviente. "La ubiestesia no está encerrada en sí misma porque aparece subordinada a un orden coincidente... La sensación no aparece como mera sensación, sino como perteneciente a un sistema de posibles cambios funcionales que lo real ha de padecer, dadas ciertas influencias. La sensación siempre es un anuncio de lo real, no se da aislada sino siempre en ese orden de correspondencia con lo real" (San Martín, J., "El contenido del cuerpo", p. 186).

${ }^{14}$ Cf. Imanishi, K., El mundo de las cosas vivientes, p. 68.

15 "Quizás no es menos absurdo dar al yo y a sus vivencias en sí mismas una ordenación en el tiempo determinado por el movimiento de la Tierra y medido por aparatos científicos. Pero cada uno dice natural y correctamente: yo soy ahora y en el mismo ahora la Tierra tiene esta y aquella posición en su trayectoria, etc." (Husserl, E., Problemas fundamentales de la fenomenología, San Martín, J. y C. Moreno (trads.), Madrid: Alianza Editorial, 2019, p. 96.) Es verdad que en la medida misma en que el yo no coincide ni colma la materialidad del cuerpo, no está por ello determinado por el tiempo de la Tierra (que no se confunde con su medida objetiva, que no es tiempo propiamente dicho) y, sin embargo, en su condición encarnada el yo dormido, el yo del impulso, el yo que siente cansancio y sueño está en la Tierra, y como cosa viva se rige también por la ciclicidad de su entorno natural.
} 
que la inserta por el cuerpo en ese ciclo vital. Además de ser un objeto de la naturaleza, un cuerpo vivo, la animalidad humana es la de un cuerpo vivido, es decir, consciente (y autoconsciente) desde una temporalidad que podemos llamar tiempo subjetivo, en contraste con el tiempo de la naturaleza (medible, objetivo), la temporalidad inmanente no solo no depende de la naturaleza y de su omnipresente ciclicidad, sino que la desgaja de sí, como la estela del cometa $^{16}$. El yo no es naturaleza, la corriente interna del tiempo que el yo unifica es temporalizante, no temporal. El cuerpo, sin embargo, la cosa viva que en el animal humano es haber y condición vivida está en el tiempo de la naturaleza, no incrustado sino eslabonado en el continuo de la vida del nacimiento a la muerte. No hay en verdad una mediación entre ambas regiones temporales, el cuerpo no es el puente ${ }^{17}$, sino la irreductible res heterogénea y, sin embargo, la subjetividad es siempre encarnada, y el yo es impensable sino situado, sino como sujeto corporal. Es probable que las habitualidades, pensadas como la estela del cometa, es decir, la huella (el tiempo) que deja el yo en el cuerpo, que traza en la materialidad que es su "haber", sean el elemento, sí, conciencial, que coloniza el mundo. Los hábitos son del yo, pero el yo deviene en su encarnación -desde un sustrato sensible originario-; los hábitos domestican el impulso y son los modos de constitución del cuerpo como haber. La historicidad del cuerpo humano, de la animalidad humana equivale a la encarnación de la subjetividad trascendental y concreción del yo como persona en sus hábitos. En la vejez, ese hiatum originario entre la ciclicidad natural y el tiempo del cuerpo se hace patente a través del desgaste.

El desgaste que caracteriza la materialidad del cuerpo en la vejez se entiende como momento natural: esperable, contenido en el origen del cuerpo vivo. No se confunde, precisamente por su condición de cumplimiento, con la disfunción, pues en última instancia el desgaste es la desembocadura normal del ciclo total o desarrollo del cuerpo como cosa viva. El desgaste tiene una referencia material pero un contenido implícito, necesariamente temporal.

\footnotetext{
${ }^{16}$ Husserl ilustra la distancia entre el cuerpo y el yo, como entre la naturaleza y el yo, con la imagen de un cometa y su estela. El cuerpo es la estela del yo, porque lo que es del yo no es ya de la naturaleza: "todo acto libre tiene su cola de cometa en la naturaleza..., él mismo no ha llegado a ser a partir de la naturaleza, sino por el yo" (cf. Husserl, E., Ideas II, p. 391).

17 "No se precisa tal nexo o vínculo -afirma Serrano de Haro- no ya por las conocidas dificultades de tender un puente entre regiones heterogéneas, sino, muy al contrario, por el hecho de que los actos, las vivencias intencionales, han tendido ya desde siempre tal puente: su esencia consiste asimismo en tenderlo". (Serrano de Haro, A., "Fundamentos del análisis fenomenológico del cuerpo" en: Serrano de Haro, A. (ed.), La posibilidad de la fenomenología, Madrid: Editorial Complutense, 1997, p. 188).
} 
La disfuncionalidad (núcleo de la enfermedad o la patología) ${ }^{18}$, en esta esfera, estribaria más bien en la imposibilidad de alcanzar la plenitud en alguna de las fases, o en su desarrollo total: "El yo espiritual [-señala Husserl-] puede así ser aprehendido como un organismo, un organismo de capacidades, de su desarrollo en un estilo normal típico con los niveles de infancia, juventud, madurez, vejez"19. Lo normal es que el cuerpo como organismo alcance el límite de todas sus fases de desarrollo. En este sentido, el desgaste es, pues, la manifestación del cumplimiento vital -últimamente- normal del cuerpo propio, y la marca más visible de la normalidad que abarca la unidad estesiológica y temporal del cuerpo vivo, la señal de su cumplimiento como agotamiento del horizonte de posibilidades de despliegue del cuerpo en términos vitales. El desgaste es una condición y/o determinación (funcional) del cuerpo como objeto y de los propios órganos y órganos sensoriales como momentos constitutivos de la materialidad cósica y objetiva del propio cuerpo. El desgaste manifiesta esa básica condición material y extensa del cuerpo como materialidad vivida, pero materialidad, a fin de cuentas. El desgaste como concepto aplicable al cuerpo vivo tendría que ubicarse en el orden de las fases de despliegue corporal, como "marchitamiento" o "acabamiento", pero acabamiento como cumplimiento de una función. La "pátina" es una categoría temporal, de la materialidad asociada al uso y cumplimiento pleno de una función, en cuanto cosa viva o viviente $^{20}$, la vivencia de este cumplimiento está entretejida con valoraciones,

\footnotetext{
${ }^{18}$ El concepto de normalidad en Husserl es básicamente equivalente al de lo óptimo, esto es, remite a una gradación en el cumplimiento correspondiente a la estructura de los actos intencionales de la percepción sensible en tal caso: "En ello, ciertas condiciones se ponen de manifiesto como las 'normales': el ver con luz de sol y cielo despejado, sin influencia de otros cuerpos que determinen el color aparente. Lo 'óptimo' que aquí se alcanza vale como el color mismo, en oposición, por ejemplo, al arrebol vespertino, que 'eclipsa' todos los colores propios" (Husserl, E., Ideas II, §18, p. 91).

${ }_{19}$ Cf. ibid., §59, p. 302. Las etapas de la normalidad de desarrollo del cuerpo que Husserl señala de modo esquemático aquí, se corresponden en realidad con las edades de cualquier cuerpo vivo y, desde luego, cualquier animal. Esto nos exige distinguir, como intento aquí, el decurso del despliegue de los procesos de su significación, en el entendido de que la naturaleza es ya la inmediatez de lo real en su coherencia experiencial e intersubjetiva.

${ }^{20} \mathrm{El}$ concepto de función se refiere aquí solo al despliegue o movimiento, la activa potencia del cuerpo propio, el movimiento en acto (e intuible) de las partes del cuerpo con relación al todo del mismo, y del cuerpo como parte de un todo más amplio que es el todo de su entorno inmediato o natural, de una naturaleza de la que el cuerpo vivo (o la cosa viviente) es función o momento. Imanishi, desde una perspectiva estrictamente filosófica -es decir, de una filosofia de la viday fenomenológicamente "sesgada", reconoce este concepto de función en el modo del enlace y engarce orgánico o funcional de los cuerpos vivos y los cuerpos no vivos: "Debido a que es inconcebible separar eso que representa el cuerpo o la estructura de las cosas vivientes, de las cosas mismas... Los animales vivientes o vuelan o nada porque están vivos. Eso es lo que significa 'viviente'. Cuando consideramos los animales vivientes en término de su cuerpo o de su estruc-
} 
significados culturales e histórico adquiridos por el yo. Este desgaste tendente al acabamiento es "natural", la experiencia valiceptiva, positiva o negativa de tal estado material es espiritual y responde a motivaciones espirituales. El marchitamiento de una flor es tan natural, o normal, como anormal es su descomposición en botón. Ahora bien, respecto del cuerpo vivido en la vejez, la negatividad con la que se viva la condición del cuerpo incide en la constitución de la identidad del yo. El desgaste es una condición básica del cuerpo en la vejez, es materia de valoraciones en las que el sujeto capta su cuerpo como envejecido, y estas valoraciones determinan el modo vital de la vejez (la manera en que envejecemos o vivimos nuestra vejez). El valor de la vejez -para el sujeto que la vive- es relativo al significado de la unidad del cuerpo y su desarrollo, y este significado es espiritual.

El desgaste no es mal ni es enfermedad, pues a diferencia de la enfermedad, que es necesariamente la obstaculización o la imposibilidad de la percepción, y del estar "normal" en el entorno de las cosas -vivas y no vivas-, la vejez es más bien la marca de una normalidad llevada a su última esfera de realización. No es disfunción patológica sino la realización continua de una función adecuada y normal ella misma. La disfunción implica una ruptura en la tendencia básica o natural del desarrollo y la plenitud funcional del cuerpo, el impulso de la continuidad de sí, de la subsistencia del propio cuerpo. La disfunción es impedimento, el desgaste, por el contrario, es la exposición final de un despliegue completo, plenificación del desarrollo corporal. El desgaste de la cosa viva deriva de las determinaciones relacionales y, por tanto, funcionales de su condición espacial, del cuerpo como Körper o como objeto que se desplaza y se despliega ${ }^{21}$. La función es siempre una determinación relacional, implica un conjunto y hasta un orden de relaciones con otros cuerpos; ese orden relacional es la función vital (en las cosas vivientes) que se cumple en la vinculación con otras cosas vivas y no vivas. El desgaste es una categoría necesariamente relacional, que remite, pues, a un vínculo vivo él mismo en cuanto dynamis, en cuanto movimiento en función: "Las cosas vivientes poseen

tura, el volar o el nadar son fenómenos que no se pueden describir bien solamente recurriendo al concepto de estructura. Estas dos acciones deberían llamarse funciones mejor que estructura... Solo una estructura que permita diferentes clases de funciones corresponde a una cosa viva" (Imanishi, K., El mundo de las cosas vivientes, p. 59).

${ }_{21}$ "Como tal, el crecimiento y el desarrollo significan el crecimiento y el desarrollo, tanto de la estructura, como de la función. Así, la relación entre una cosa viviente y estas células, equivale a la relación entre el todo y las partes de una integridad que sostiene el crecimiento y el desarrollo, tanto en la estructura como en la función dándosele el nombre de 'cosa viviente', a esta entidad orgánicamente integrada" (ibid., p. 60). 
estructura y función como un conjunto único de la misma manera que poseen cuerpo y vida; como tales pueden constituir este mundo" 22 .

La materialidad desgastada implica la fragilidad de futuro: lo raído, lo deslavado, lo decolorado -así considerado desde un cierto punto culminante de diafanidad- expresa un futuro angostado en la densidad de su pasado. La fragilidad tiene un contenido material de pasado, y un cumplimiento igualmente manifiesto en el desgaste. La fragilidad (tan material como temporal) es el contrapolo significativo del desgaste. Como la inmanencia del tiempo subjetivo, es el contrapolo (el cometa) de la estela de naturaleza que traza.

\section{Fragilidad de futuro}

En la vejez la indeterminación del mundo se tamiza a través de la propia sedimentación de la experiencia en que el sujeto ha configurado su identidad $y$, conforme a ella, una estilística perceptiva, representativa, rememorativa $\mathrm{y}$, desde luego, proyectiva de la propia vida. Esta proyección irradia desde el propio cuerpo, de sus posibilidades de despliegue y desarrollo. En la vejez, esas posibilidades y determinaciones se perfilan más claramente en el "espesor" de la experiencia sedimentada, que orienta los comportamientos y pauta los significados del desgaste de la materialidad corporal. Al desgaste de la piel, de la carne como exhibición natural del tiempo del cuerpo, de su desarrollo cumplido, le es correlativo, del lado del yo, del tiempo subjetivo, un cúmulo de experiencias pasadas en cuyo fondo se recortan las posibilidades de la experiencia presente y el alcance de las proyecciones a futuro: "La expectativa no es en lo general univoca: tiene sus horizontes aperceptivos de determinabilidad indeterminada en el interior de un marco intencional delimitante; concierne precisamente a una de las maneras de comportamiento, la cual corresponde al estilo"23. La indeterminación que caracteriza al horizonte de futuro hasta cierto punto de la plenitud adulta se estrecha en la vejez por razón de los cumplimientos pasados de experiencias semejantes y hasta por una suerte de reforzamiento o consolidación de los vínculos asociativos, de los rieles mismos de la asociación, las motivaciones y las sedimentaciones de todas esas experiencias pasadas, semejantes, del mismo tipo y, por así decir, cada vez más plenas o colmadas de contenido, de tal modo que el contrapolo de esa "solidez" experiencial o acumulada, es la determinación cada vez mayor del horizonte de indetermina-

22 Ibid., p. 63.

${ }^{23}$ Husserl, E., Ideas II, p. 318. 
ción del futuro24: La persona se forma por "experiencia”... Aquí el concepto de experiencia es sin duda distinto de aquel en el cual se habla, en contextos de validez, de fundamentación del conocimiento por experiencia... Pertenece a la vida personal una tipología que es distinta para cada una. Dentro de ciertos trechos esta tipología permanece la misma, incluso cuando las "experiencias" (el dominio de las apercepciones de experiencia que se forman siempre de nuevo) de la persona crecen, y con ello se altera el dominio de las predaciones ${ }^{25}$.

Este "crecimiento" es acumulativo y modula en su grosor la expectativa abierta o indeterminada de cada vivencia -dentro de un tipo-. La fragilidad del horizonte de futuro no se refiere, al menos no primariamente, a las posibilidades de su cancelación por la inminencia de la muerte (que no es nunca una posibilidad real o efectiva para el yo, sino siempre y necesariamente indirecta y mediada por las experiencias y representaciones de otros); se trata más bien de una fragilidad de lo posible relativa a las posibilidades del cuerpo. El cuerpo no puede esto o aquello en el mundo inmediato, pero de un modo tal que esa posibilidad ha sido antes cumplida o realizada, no en el de la mera disfunción. El yo puedo es frágil; es fragilidad del yo en el desgaste de su cuerpo, pero también, de la novedad, de lo nuevo e indeterminado para el yo, siempre en relación con la experiencia sedimentada.

La fragilidad de futuro se refiere así a la plenitud de los contenidos de pasado que angostan la apertura de lo posible que caracteriza al futuro en cuanto tal. Y podemos delimitar esa esfera de posibilidades en relación con el propio cuerpo: la experiencia vital de la juventud, el cumplimiento productivo y reproductivo de la vida adulta, etcétera. Esas posibilidades corporales cumplidas, ya realizadas son las que angostan las posibilidades restantes, por así decir, en el desarrollo del propio cuerpo. La fragilidad de lo posible es erosión en la continua determinación del orden de posibilidades en relación con un contenido que predelinea y determina lo esperable de la experiencia del cuerpo. Toda posibilidad se abre dentro de los límites de un cierto marco de determinación (y determinación en ciertos tipos), de predelineamiento del curso experiencial en referencia a expectativas fundadas en experiencias previas ${ }^{26}$. La fragilidad de lo posible estriba en la estrechez de la apertura en lo determinado,

${ }^{24}$ Cf. Husserl, E., Experiencia y juicio, p. 36.

${ }^{25}$ Cf. Husserl, E., Ideas II, §60, p. 319.

${ }^{26}$ Las sedimentaciones y orientaciones habituales que forman el contenido de la experiencia "llenan" la estructura misma de la correlación: "De este modo, una estructura fundamental de la conciencia del mundo, o sea, en una formulación correlativa, del mundo como horizonte de todas las realidades individuales experimentables, es la estructura de lo conocido y lo desconocido con 
en relación directa con el espesor de los contenidos de la experiencia personal sedimentada. Esta determinación cobra un mayor peso sobre el tejido de anticipaciones y proyecciones propias del sujeto, en la medida en que establece las condiciones esperables del curso de cada experiencia, o se reafirman las habitualidades de los cursos de percepción y espera.

La indeterminación que envuelve las expectativas de la juventud tiene su fuente de sentido en la relativa vacuidad experiencial que estrecha los limites biográficos del pasado, mientras en la vejez esa indeterminación se perfila de un modo cada vez más claro en relación con experiencias anteriores (del mismo tipo, del mismo objeto, bajo la misma estructura), esto es así por la propia estructura asociativa de la experiencia ${ }^{27}$.

La fragilidad de lo posible significa el declive de la novedad y de la espera de la novedad. Si la novedad se define como la mayor indeterminación de ciertas expectativas dadas desde una determinada orientación, el cúmulo sedimentado de experiencias que individualizan (en las que se concreta) al sujeto como persona, con su biografia y experiencias intransferibles, motivaria cierto desgaste de la novedad como sentido indeterminado, no reconocible de algún modo. La experiencia en su sentido acumulativo, como continua reactivación asociativa de sentido, revela en la vejez el más claro de sus significados, el de la plenitud de un contenido que opaca y transparenta las posibilidades de futuro. Opaca el sentido de la novedad, es decir, y transparenta el contenido anticipado de la posibilidad en cuanto tal, los contenidos esperables. No obstante, la estructura de la experiencia permanece continua e infinitamente abierta e inagotable.

La fragilidad de lo posible en relación con la vejez se define a partir de las experiencias que trazan los caminos del desenvolvimiento activo del sujeto en su circunstancia. No solo se limita el horizonte de lo posible, en tanto casi desplazado por un horizonte de lo determinado, de lo pretrazado o reconocible por un yo, sino que ese yo, en cuanto tal, ha quedado ya determinado en sus desenvolvimientos por ese mismo curso experiencial28. No solo el sentido de

su correspondiente relatividad continua y su no menos continua diferenciación relativa entre generalidad indeterminada y particularidad determinada" (Husserl, E., Experiencia y juicio, p. 39).

27 "El principio universal de la génesis pasiva para la constitución de todas las objetividades, en cuanto previamente dadas al configurar activo, lleva el título de asociación” (Husserl, E., Meditaciones cartesianas, Presas, M. (trad.), Salamanca: Ediciones Paulinas, 1979, § 39, pp. 136-137). La asociación que rige la esfera de la pasividad articula los modos de la expectativa con los contenidos de la experiencia pasada, en tipos que trazan modos habituales sobre lo esperable.

${ }^{28} C f$. Husserl, E., Experiencia y juicio, p. 36. 
los objetos y sus revelaciones paulatinas queda pre-establecido por la sedimentación experiencial de la vejez, sino el propio curso, el desarrollo mismo de la actividad subjetiva (y de su pasividad incluso) queda así predelineado sedimentariamente en el estilo29. "El mundo es el 'espacio de juego' dentro del cual se toma una posición, y, por el otro, el mundo no es algo dado y constrictivo sino el 'estilo de vida' que resulta de las posiciones que ha adoptado un yo cuyas posibilidades no existen en sí, sino que son tales en la medida en que son apropiadas y realizadas. Enfocado como condición, el mundo es el espacio de juego para las operaciones de la subjetividad trascendental. Contemplado como resultado, el mundo es el 'estilo de vida' que se ha configurado a lo largo de la historia del sujeto"30.

El sí mismo de la vejez se reconoce en su estilo de vida: la orientación (inclinación) de sus actos, de las reacciones y estados que se desprenden de cierto estado de cosas dado, está predelineado en el horizonte habitual de toda una vida pasada, del horizonte de posibilidades de realización subjetiva que en la vejez se revelan solo desde su condición de haberse dado antes, desde la condición misma del re-conocimiento, de la vida que vuelta sobre sí se ve como la misma -y como distinta- desde el pasado ${ }^{31}$.

La fragilidad de lo posible equivale al desgaste de la novedad, a su estrechez y, en la manifestación del tedio, su total pérdida, en relación inmediata con el interés del sujeto por lo que representa la novedad, o por la apertura de la posibilidad en cuanto tal. Esto significa que, si mientras en la juventud la novedad y la búsqueda de la novedad son motivaciones experienciales con una centralidad relativa, en la vejez la novedad, siempre referida a un contenido ya vivido, puede despertar, más que el interés del sujeto por lo nuevo -o lo posible en su indeterminación-, el tedio por lo ya visto y ya experimentado de diferentes

${ }^{29}$ Cf. Husserl, E., Ideas II, § 60, p. 318.

30 Walton, R., Mundo, conciencia y temporalidad, Buenos Aires: Almagesto, 1993, p. 22.

${ }^{31}$ Es necesario reconocer aquí el fundamento de uno de los rasgos históricos comunes a casi todas las sociedades tradicionales y ágrafas en las que los ancianos adquieren un poder político y social al ser considerados la memoria viva de la comunidad, tal como podemos recuperarlo de la historia cultural de la vejez: "El viejo de ciento diez años de la inscripción mastaba de Ptahetep es igualmente un mago, y entre los persas es un hombre de avanzada edad, Artabán, el encargado de interpretar los sueños del dios Jerjes. Está considerado, al mismo tiempo, como el hombre memoria de la dinastía" (Minois, G., Historia de la vejez. De la antigüedad al Renacimiento, Madrid: Nerea, 1989, p. 390). A esta condición del "experimentado", el hombre o la mujer de "experiencia" se asocia la sabiduria, en tal caso, enteramente práctica, devenida de la práctica del sujeto en el mundo. En realidad, y como nos lo hace ver la historia de Minois, la asociación entre vejez y decadencia, con el paralelo culto a la juventud y la belleza, aparece tematizada y explícita en las ciudades-estado de los griegos. 
maneras, en orientaciones diversas: en la decepción y la satisfacción, la expectativa y el cumplimiento. De tal suerte, la novedad y la espera de la novedad en cuanto tal pueden verse desplazadas por el tedio, directamente relacionado con la posición del sujeto en el decurso de su propia vida, es decir, determinado por el orden de significados históricos, de representaciones culturales tanto del tedio como de la novedad, del cansancio y de la juventud, de la plenitud y del desgaste. El valor de la vejez y la experiencia de la vejez son relativos a una idea amplia de la vida, no solo de la existencia, sino de la vida en cuanto dynamis o despliegue de la naturaleza, o concepción (también científica) de la naturaleza como movimiento y transmutación.

El desgaste expresa una cierta fragilidad de futuro que se distingue claramente de la incertidumbre que bordea el despliegue de la juventud o de la plenitud adulta. Esto significa que cada fase de la vida o "edad del cuerpo"32 tiene una determinada contextura temporal, una composición horizóntica específica o determinada para cada caso. Si la incertidumbre es una característica determinante del horizonte de futuro en la juventud, su correlato está en la estrechez del pasado acumulado. La vejez se caracterizaría por la estrechez del horizonte de futuro, en contraste con la extensividad y profundidad mucho mayor del horizonte de pasado manifiesto, como antes vimos, en la condición desgastada de la materialidad del cuerpo. El horizonte temporal de futuro en la vejez está directamente asociado al pasado que condensa el desgaste. Si el futuro se entiende como el horizonte de expectativas, de posibilidades de cumplimiento y realización de tendencias propias del cuerpo vivo, ese horizonte en la vejez se manifiesta en su compleción, en su cumplimiento para el yo encarnado, como yo en el haber de su cuerpo. Las posibilidades que integran el contenido de las expectativas y proyecciones de futuro, en la vejez se manifiestan como

\footnotetext{
32 Aristóteles se refiere a las "edades del cuerpo" como edades del desarrollo. En el libro V de la Reproducción de los animales ("Sobre las partes de los animales"), Aristóteles dedica alguna reflexión a la vejez caracterizándola como enfermedad y anormalidad. No obstante, señala el enfriamiento como tendencia normal de cualquiera de las edades; en su negatividad el enfriamiento equivale a decaimiento del cuerpo. Esto significa que para Aristóteles la vejez sería un estado de "enfermedad" normal, en el sentido de esperable: "En cambio, la blancura de los cabellos a causa de la edad se produce por debilidad de una piel enferma y blanca también enferma al mismo tiempo, y la enfermedad del pelo es la canicie. En cambio, la blancura de los cabellos a causa de la enfermedad se produce por debilidad y falta de calor. Efectivamente, cualquier edad tiende al enfriamiento cuando el cuerpo decae, y también la vejez: pues la vejez es fria y seca" (Aristóteles, Sobre la reproducción de los animales, 784a, Sánchez, E. (trad.), Madrid: Gredos, 1994, p. 304) En la asociación casi natural entre vejez y enfermedad (como anormalidad) coincide casi toda la tradición occidental que ha tocado el tema. Desde Aristóteles hasta el siglo XX con Simone de Beauvoir, quien caracteriza la vejez como un estado de "anomalía normal" (Véase: Beauvoir, S., La vejez, Bernárdez, A. (trad.), México D.F.: Penguin, 2019, p. 355).
} 
posibilidades referidas a un cumplimiento ya dado, esto es, como dadas en cuanto reconocidas o reconocibles. En la vejez las posibilidades del horizonte futuro se presentan no desde su apertura sino desde sus determinaciones ya probadas o conocidas, como despliegues posibles de un curso de experiencia efectivamente vivido antes, en otro modo y momento de la experiencia.

$\mathrm{El}$ horizonte de mundo es siempre (y necesariamente) el horizonte de posibilidades de acción y realización del sujeto desde tendencias inscriptas en el cuerpo vivo, en su constitución física normal, o desplegable desde sí misma y sin obstáculos externos. El mundo es, pues, un horizonte determinado indeterminado, la apertura de la vida misma como experiencia (y experiencia de sî) cuya única determinación es la infinita apertura o indeterminación que se corresponde con las propias determinaciones (indeterminadas) del cuerpo vivo (vivido, humano). Es el mundo, acaso, lo que se desgasta o se deslava, en cuanto horizonte de posibilidades siempre nuevas. Un desgaste correlativo al de los órganos sensibles y las capacidades del cuerpo.

La patencia del desgaste es el pasado, que otorga un cierto volumen (una solidez palpable) al yo -en la retracción de ese horizonte extensivo e intensivo del cuerpo vivo-. El desgaste condensa un despliegue funcional y de uso. Como núcleo radial de una cierta narrativa vital, biográfica (y con ello autoconstituyente, identitaria), el desgaste está volcado al pasado, o en el pasado como el tiempo que llena -o desborda- el contenido del cuerpo. El pasado se espesa en el desgaste (en todo su esplendor opaco y sucio), desde donde irradia también la fragilidad del futuro. Si el desgaste representa la solidez de un pasado acumulado en una experiencia sedimentada que alimenta y engrosa la individualidad inintercambiable (e infranqueable) del sujeto, su cara opuesta, la otra cara de la moneda es la fragilidad, pero ya no en términos pura o meramente materiales, sino temporales. La solidificación de la experiencia patente en la materialidad desgastada del cuerpo es correlativa a la fragilidad que se extiende desde este punto hacia el futuro, en limitado porvenir del cuerpo propio; limitado en el cumplimiento de las fases, edades de desarrollo que le preceden. La fragilidad de futuro sería, así, el modo, la orientación autoconstitutiva del yo a través de su cuerpo desgastado.

\section{La identidad del yo en la vejez}

La animalidad en el humano es siempre una condición significada, esto es, historizada en un horizonte intersubjetivo; en una realidad de sentido que no ha sido creada ni puede ser conjurada por el yo, pero que tampoco puede 
asumirse ni explicarse sin más como el determinante absoluto del desarrollo de la vida individual ${ }^{33}$. La vejez, al igual que la juventud y la plenitud adulta, están histórica y culturalmente pautadas, tienen un significado que arraiga en el orden de relaciones que los sujetos establecen y mantienen con su entorno natural y social, en sus entretejimientos reciprocos. Lo verdaderamente relevante en tal caso es el modo en el que tal significado brota y se articula en la materialidad del cuerpo. Esto es, que fenomenológicamente no basta con el reconocimiento del carácter o la dimensión cultural y de significado del cuerpo vivo como cuerpo propio; lo que en verdad se hace necesario es la exposición de los modos mismos de la apropiación o significación del cuerpo desde la centralidad decisiva del yo: "Además, tengo -así lo encuentro- un cuerpo que es una cosa entre otras que yo igualmente encuentro. Y esto también lo hago en el tiempo: en el ahora, el cuerpo existe en este momento como mi cuerpo; hace un momento, el cuerpo que ha sido hace un momento; en el recuerdo, el cuerpo rememorado; continuamente me pertenece el cuerpo"34.

Pero en el recuerdo, lo rememorado del cuerpo que es el mismo y que permanece, adquiere un cierto valor y un nuevo modo de apropiación, re-apropiación o desapropiación por el yo: "Habría que explicar algo más: la cosa que cada yo encuentra como "su cuerpo" se distingue de todas las restantes como cuerpo propio (Eigenleib) que siempre e inevitablemente se encuentra ahí en la esfera perceptiva actual, que es percibido de un modo propio (a describir con más exactitud) y es el miembro central permanente de la comprensión del entorno cósico"35.

La apropiación del cuerpo vivo, en su condición de cuerpo vivido, es el proceso por el que los significados culturales y espirituales se encarnan, se materializan en la carne autosintiente como medio de la voluntad. La apropiación es el modo de inserción de la carne en el tiempo histórico, es decir, de espiritualización del cuerpo. La propiedad del cuerpo implica su significación, el conjunto de valoraciones que acompañan y "envuelven" sus estados, como estados materiales y como estados anímicos. La apropiación es el dar sentido al cuerpo de propiedad bajo una orientación intersubjetivamente pautada,

\footnotetext{
${ }^{33}$ A esto le podemos llamar, con Husserl, humanización del mundo: "El mundo es un mundo humanizado, un mundo animalizado que se presenta como tal en cada mundo actual de la vida o de la experiencia, en cada fase del mundo histórico dentro de nuestro contexto generativo. Se trata de un mundo de la cultura" (Husserl, E., "Monde humain, monde animal, monde préhistorique", en: Philosophie, 131 (2016), Alloa, E. (trad.), p. 21).

${ }^{34}$ Husserl, E., Problemas fundamentales de la fenomenología, 2, p. 88.

35 Ibid., p. 81.
} 
esto es, bajo una orientación histórica o espiritual, la propiedad deviene en la incidencia de la sensibilidad secundaria sobre el sustrato material más básico del cuerpo vivido.

Las edades del cuerpo son los marcos de significado de la condición vivida del cuerpo propio. Pautan un horizonte de significado, que como tal es ya histórico, intersubjetivamente configurado, como modos de vivir la juventud, la plenitud adulta y la vejez, como modos de valorar y servirse del cuerpo en cada momento. Las edades serían, pues, el marco de usos prácticos y referentes simbólicos de la apropiación del cuerpo vivo. La vejez es la experiencia pautada o significada del desgaste del cuerpo y del futuro colmado que el desgaste refleja, y su diversidad es rastreable tanto espacial como temporalmente, ya como sabiduria, ya como enfermedad. La vejez es un foco de significado, como la juventud, variable a través del desarrollo y entrelazamiento biográfico de los sujetos en el horizonte más amplio de la socialidad humana. Las edades del cuerpo se configuran como campos de significado de la voluntad y las capacidades del yo en relación con la materialidad de la carne.

La apropiación del cuerpo exhibe la radical diferencia entre el yo y su cuerpo y, en esa medida, es también un acto enajenante, en el que no necesariamente coinciden, y en el que se identifican ambos polos: la conciencia y el cuerpo. La apropiación implica en sí misma una desapropiación, la exhibición de la no correspondencia originaria entre la materialidad de la carne y la voluntad del yo. El cuerpo propio es más que el cuerpo vivido, es el cuerpo como haber del yo y como órgano de una voluntad a la que también se resiste o puede resistirse, porque tal condición no lo agota ni lo determina en sentido absoluto.

La autopercepción, como la percepción sensible, por ejemplo, tiene una estilística y una orientación determinada desde la base sedimentaria de la experiencia -acumulada- de la vida subjetiva, es decir, el sujeto constituye su propia identidad desde el marco de referencias históricas, significativas de la materialidad del cuerpo vivido, se concreta así la apropiación en la configuración valorativa de las condiciones dadas de la propia vida. Entonces, los elementos que hasta aquí hemos propuesto como determinantes de la vejez -el desgaste y la fragilidad del futuro, como afluentes del tiempo del cuerpo y el tiempo del yo- no son solo los modos de una experiencia que orienta el estado del cuerpo en el mundo, sino que son valorados, determinados desde una disposición igualmente sedimentada. La vejez, dicho de otra forma, es aceptada (aceptable) o negada (negable), vivida de una cierta forma, desde una cierta orientación fundada en la valoración más amplia de las determinaciones del desgaste y la 
fragilidad del futuro. De un modo mucho más enfático que otras edades del cuerpo, la vejez es tematizada por el yo debido al desplazamiento del cuerpo desde el fondo anónimo de la experiencia, hacia un plano primario de atención.

El cuerpo en el desgaste -como en el dolor- se resiste a la apropiación, pero solo si tal resistencia es la pauta y marca histórica, espiritual, o una parte, al menos, de la estilística con la que el sí mismo se capta en la vejez. Lo históricamente pautado es la valoración de los contrapesos de pasado y futuro en el desgaste, y como tal es descriptible en sus estructuras desde los vínculos interpersonales, e intergeneracionales del entorno cultural. Del mismo modo, la autopercepción corporal como ingrediente de la autocaptación identitaria del yo se da bajo cierta orientación o sesgo valiceptivo histórica y estilísticamente pautado.

“...Sobre el soporte del representar meramente intuitivo se edifica el valorar, que, si lo presuponemos, desempeña en la inmediatez de su motivación viva el papel de una "percepción"-de-valor [en nuestras palabras: valicepción] en la cual el carácter de valor está dado él mismo de modo primigeniamente intuitivo. Al escuchar el sonido de un violín, está dada originariamente la gracia, la belleza..."36. La valoración negativa del desgaste en la vejez es elemento espiritual de la constitución identitaria del yo, como el orgullo que acompaña la plenitud física de la juventud, o la vergüenza la configuración de la autocaptación del cuerpo sexuado como femenino. La diferencia específica de la vejez consistiría en este rasgo alienante, pero solo bajo la condición de ser reconocido en sus limites históricos, es decir, como insertos en el orden de significados de nuestro tiempo, lo que no descarta, o mejor aún, nos permite incluir otras posibilidades apropiadoras, y valorativas del desgaste, o bien nos hace asequible una historia de la vejez, de la fragilidad y el tiempo del cuerpo.

En la vejez la condición material del desgaste genera este campo de atención centralizante del cuerpo y, por lo tanto, de polarización del yo y su cuerpo, y esto aparece ya como una marca asequible de la vejez en términos objetivos, en continua rebelión respecto de la apropiación del yo a través del esfuerzo. La vejez se constituye, pues, desde el núcleo de un cuerpo materialmente desgastado y temporalmente frágil, pero, sobre todo, un cuerpo significado en la vida.

${ }^{36}$ Husserl, E., Ideas II, p. 232. La primera definición aparece en el § 4, p. 39. 


\section{Conclusiones}

La romantización de la vejez, tanto como su patologización, exponen modos de apropiación históricamente pautados, no simplemente desde un discurso biomédico o político sobre la vejez, sino desde la comprensión más extensa de la vida como continuidad progresiva hasta la decadencia, o la restauración cíclica como tendencia de todo lo viviente. El viejo no es un enfermo, ni un paciente, o solo será constituido así, solo tendrá este significado la vejez, en un horizonte histórico en el que la vida sea un mediodía estancado -sin arborescencias-, un mundo en el que la muerte haya sido definitivamente expulsada de la vida.

Es necesaria una fenomenología de las edades del cuerpo en un contexto en el que la patologización de ciertos estados corporales y disposiciones egoicas motiva la marginación de los sujetos del orden social o de sus respectivos órdenes de mundo. La patologización histórica de la vejez ha motivado la marginación social de sujetos concretos. La vejez como enfermedad no se funda en la determinación de un límite etario, sino en la patologización del cambio y la transformación, contrapunto evidente del culto a la novedad. La valoración negativa del desgaste y la determinación meramente temporal de la fragilidad fundan la visión patológica de la vejez y determinan la experiencia de los sujetos desde la valoración o dis-valoración de su cuerpo.

La historia del yo se entendería así como el decurso de la encarnación, si esta, a su vez, puede ser vista como el continuo despliegue, es decir, separación y desprendimiento, como la estela de las temporalidades del cuerpo y del yo que en la vejez, finalmente, se intersectan de algún modo, el modo en el que el tiempo del yo cruza, atraviesa perpendicularmente, la muerte.

Recibido: $15 / 02 / 2021$

Aceptado: 07/06/2021

434

\section{Bibliografia}

Aristóteles, Sobre la reproducción de los animales, Sánchez, E. (trad.), Madrid: Gredos, 1994.

Beauvoir, S., La vejez, Bernárdez, A. (trad.), México D.F.: Penguin, 2019.

Cassirer, E., Filosofía de las formas simbólicas II, México D.F.: Fondo de Cultura Económica, 2001. 
Husserl, E., Experiencia y juicio. Investigaciones acerca de la genealogía de la lógica, Reuter, J. (trad.), Navarro, B. (rev. trad.), México D.F.: UNAM, 1980.

Husserl, E., Ideas relativas a una fenomenología pura y una filosofía fenomenológica, Libro II, Investigaciones filosóficas sobre la constitución, Zirión Quijano, A. (trad.), México D.F.: Fondo de Cultura Económica, 2005.

Husserl, E., "Monde humain, monde animal, monde préhistorique", en: Philosophie, 131 (2016), Alloa, E. (trad.), pp. 19-24. https://doi.org/ 10.3917/ philo.131.0024 Husserl, E., Lecciones sobre la conciencia interna del tiempo de 1905, Serrano de Haro, A. (trad.), Madrid: Trotta, 2002.

Minois, G., Historia de la vejez. De la antigüedad al Renacimiento, Madrid: Nerea, 1989.

Pickard, S., "Health, Illness and Frailty in Old age: a Phenomenological Exploration", en: Journal of Aging Studies, v. XLVII (2018), pp. 24-31. https://doi.org/10.1016/j. jaging.2018.10.002

San Martín, J., "El contenido del cuerpo", en: Investigaciones Fenomenológicas, v. monográfico II: Cuerpo y alteridad, Madrid: UNED-SEFE, 2010. https://doi. org/10.5944/rif.2.2010.5578

Serrano de Haro, A., "Fundamentos del análisis fenomenológico del cuerpo" en: Serrano de Haro, A. (ed.), La posibilidad de la fenomenología, Madrid: Editorial Complutense, 1997, pp. 185-216.

von Uexküll, J., Andanzas por los mundos circundantes de los animales y los hombres, Guntin, M. (trad.), Buenos Aires: Cactus, 2016. 